\title{
Public-private health care delivery becoming the norm in Sweden
}

A t first glance, the Sabbatsbergs Närsjukhus Hospital in central Stockholm is indistinguishable from the medical centres that together form the front line of Sweden's vaunted health care system.

Its facilities, offering specialized services but no emergency room, are busy with patients who appear to be making use of a public hospital.

But looks can be deceiving. Once a government-managed facility, Sabbatsbergs today is - like nearly one quarter of primary care facilities in Sweden, and like nearly half in Stockholm privately run, and has been since the mid-1990s.

This hospital, tucked amongst the low-rise heritage buildings of central Stockholm, is part of a growing trend in Sweden, where medical services are increasingly being provided by privately run, but publicly funded clinics in a country famous for its universal health care system.

And compared to the controversy surrounding private health care in other countries, in Sweden, of all places, the private sector has taken on a larger role with relatively little fanfare.
For decades, Sweden has been the global bastion of socialized health care. In many ways, it still is. But as countries the world over struggle with rapidly changing technologies, spiking medical costs, rising demands for service with noncorresponding appetites for increased fees or taxation, Sweden is increasingly turning to the private sector to reduce the burden on a health care system at risk of being crushed under its own weight.

"Many of the developments in the last 15 years have been about going from a government-funded system to a more open system that includes the private sector," says Dr. Birger Forsberg, a professor of international health at the Karolinksa Institute medical school who also advises Stockholm on health care policies.

The Scandanavian model of a welfare state built on high taxation is known the world over, especially in countries, like Canada, that have adopted various forms of the system.

In fact, Sweden's success at adopting a public-private hybrid was cited by the Supreme Court of Canada in its 2005 decision to strike down prohibitions against private health care insurance in Quebec, saying that countries

\author{
Facts on Sweden \\ Demographics \\ - Area: 449964 km² \\ - Population: 9045389 \\ - Median age: $41.3 \mathrm{yr}$ (40.2 male, 42.4 female) \\ Age structure: $16 \%$ under 15, $65.6 \% 15-64 \mathrm{yr}, 18.3 \%$ over 64 \\ - Birth rate: 10.15 births per 1000 population \\ - Death rate: 10.24 deaths per 1000 population \\ - Infant mortality rate: 2.75 deaths per 1000 live births (2.91 male, 2.58 female) \\ Life expectancy: 80.74 yr (78.49 male, 83.13 female)

\section{Economy} \\ - Gross domestic product per capita: US\$334.6 billion (2007 estimate) \\ - Unemployment rate: $6.1 \%$ (2007 estimate) \\ - Population below poverty line: not available \\ - Government revenues: US\$253.4 billion (2007 estimate) \\ - Government expenditures: US\$240.5 billion (2007 estimate) \\ - Public debt: $41.2 \%$ of gross domestic product (2007 estimate) \\ Health \\ - Total health expenditures as a percentage of gross domestic product: $9.5 \%$ \\ - Government share of total health expenditure: $85.9 \%$ (2002) \\ - Per capita total expenditure on health: US\$2517 (2002) \\ - Density of physicians per 100000 population: 304.1 (2000) \\ - Density of nurses: 975.1 (2000) \\ Sources: Central Intelligence Agency World Factbook, World Health Organization.
}

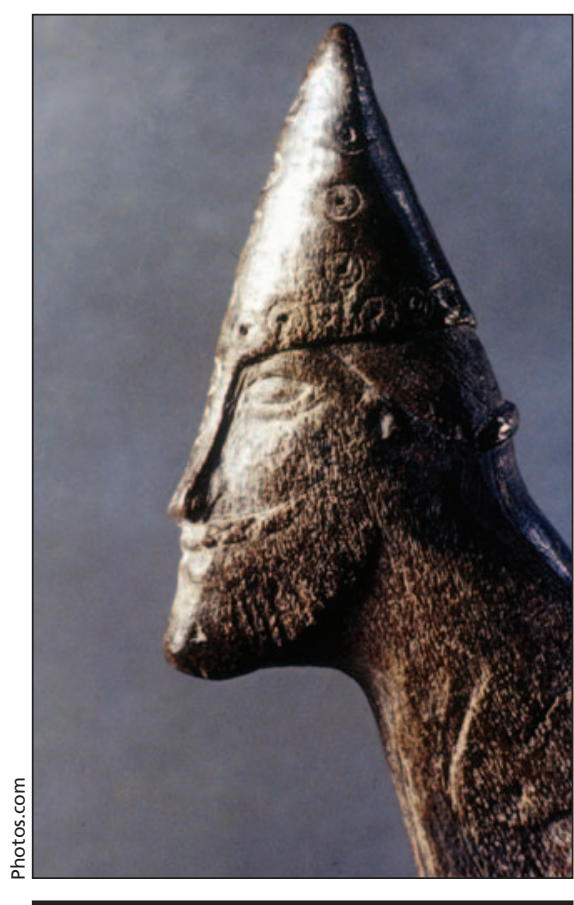

Sweden is almost as famous for its universal health care system as its artifacts, like this Viking helmet displayed at the National Historical Museum. Now, it's becoming renowned for the extent of private involvement in the publicly funded system.

such as Sweden and Germany, that allow private insurance, have successfully delivered medical services that are superior to and more affordable than services available in Canada.

About $18 \%$ of overall health spending in the country comes from the private sector, according to the World Health Organization. But on top of that, private companies compete alongside public facilities for government funding and the right to provide health care to Swedish citizens.

The winning bid - whether public or private - receives government funding with the goal of leaving the end service (in other words, what the patient sees) unchanged, regardless of the service provider, while rewarding those who can provide the quickest and cheapest treatment.

According to the most recently available survey, 250 such privately run but publicly funded clinics operate in the country, representing $24 \%$ of the country's health centres. That's up from 146 private clinics representing $14 \%$ of overall health centres in 2000 , 


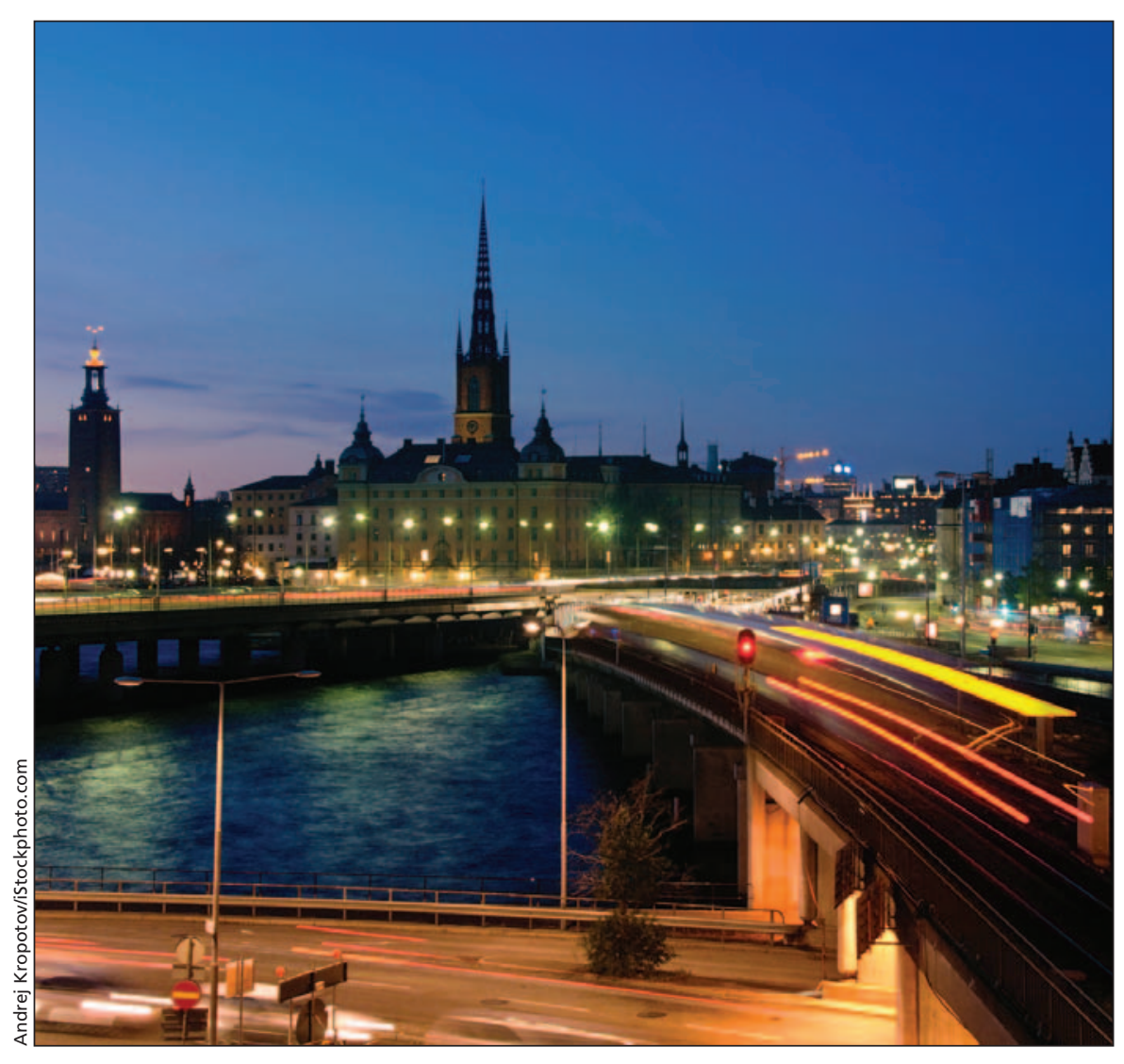

Nearly one-half of primary care facilities in Stockholm are now privately run, an almostshocking statistic for a city and a country that has been the archetype for a welfare state built on high taxes. Located on Sweden's east coast, the central parts of Stockholm consist of 14 islands. The geographical centre of the city is essentially located on water, in the Bay of Riddarfjärden.

according to Sweden's Association of Private Care Providers.

In addition, the country has 9 fully private, fee-for-service hospitals that operate parallel to the public system.

Sweden is perhaps an unexpected place to find such a mix of public and private health care. But experts here say the country has been forced well past the point of debating the merits and risks of incorporating private health care because Sweden faces such extreme accessibility problems and a rapidly aging population.

"Today the discussion is not whether private health care should have a role in the system, but rather what role private health care will have," says Klas Öberg, of Sweden's National Board of Health and Welfare. The board studies health care services in each of Sweden's 21 county councils responsible for delivering health care and advises the federal government on policy changes and developing trends.

Accessibility issues have been at the core of many health care policy shifts in Sweden of late. Therefore, recent changes like a policy to allow patients to seek care from physicians anywhere rather than being tied to one doctor are geared more toward reducing wait times than reducing costs.

Earlier this year, the National Board of Health and Welfare found that nearly $45 \%$ of patients have longer wait times than are supposedly guaranteed by the health care system. This, despite a recent influx of 250 million Swedish kronor (\$42 million) into reducing wait times.

"These figures are not satisfactory," Swedish Health Minister Göran Hägglund, said in February when the findings were released. "They show that we haven't approached the problem of availability with the level of force needed. ... The wait to receive attention — be it a telephone call to a local clinic or a first visit to a physician — is simply too long."

The accessibility problem highlighted by the health minister is not going to go away, with a growing demographic challenge similar to that emerging in many Western countries.

Besides a senior citizen population that has grown by more than 10000 since 2000 (to more than 300000 total), the Swedish Association of Local Authorities and Regions expects the country's overall population to grow by 870000 before 2030 , only 75000 of whom they predict will be active in the workforce.

"We're facing a situation where fewer are paying for more services, and where expectations for welfare services continue to increase steadily," says Anette Åkesson, a member of the Association's welfare financing committee.

Such growth stokes fears of what will happen to a system already overburdened by too many people seeking services from too few medical practitioners. In an attempt to address that influx, the system is turning increasingly to the private sector in the hope that the answer can be found among those with an eye for results, and the bottom line.

Compared to the sensitivity surrounding the public-versus-private health care debate in Canada, Sweden has thus far managed to introduce an increasingly hybrid system with relatively little controversy.

The differing tones of the debate between public and private - hot under the collar in Canada and shrugging shoulders in Sweden - is partly explained by the way in which the Swedish government has approached the issue. It has allowed the 9 private, fee-for-service hospitals to open for business, with little handwringing. But the largest role for private medicine is in the public sector, where the privately run facilities receive public funding to provide citizens much the same services they would at government hospitals.

Within that system, citizens in government-funded clinics are charged user fees that account for about $5 \%$ of overall health funding, while the government contributes the rest.

Hospital stays cost about \$13 a day. Patients are charged about $\$ 20$ for each 
doctor visit, and about twice that to see specialists. But after $\$ 150$ in 1 year, visits are free, and no citizen pays more than $\$ 300$ per year including prescription drugs.

The country's drugstores are government-run, though the first private pharmacies are slated to open by January 2009.

Emergency services remain the domain of public hospitals, but as the tone of debate over public versus private health care in Sweden softens, there are fewer and fewer sectors of the system that are off-limits to private companies.

"What couldn't be said 20 years ago can be said today," Forsberg says. "The ideology is not so important any more, it is just a matter of figuring out how to get the system to work." - Christopher Mason, Stockholm, Sweden

DOI:10.1503/cmaj.080877

\section{FOR THE RECORD}

\section{Open doors}

$\mathrm{F}$ ast-tracking the licensing of doctors already certified in the United States or other countries that have practice and education standards equivalent to those of Ontario, and modifying the transitional licensing system to ease entry for internationally trained doctors from countries with different training systems than Canada, are among measures proposed by Ontario Health Minister George Smitherman to increase the number of foreign-trained physicians allowed to practise in the province.

Smitherman says the government will introduce legislation this summer to implement recommendations urged by Laurel Broten, parliamentary assistant to the Ministry of Health, in a report on measures to increase the number of international medical graduates practising in Ontario.

Broten's 5-point action plan urged fast-tracking registration of doctors coming from comparable health care systems, which would open up transitional licenses for so-called "possible practice" physicians, who need to com- plete certain educational requirements, or undertake a measure of training that would bring their credentials up to par with those of Canadian-trained doctors. The transitional licences would allow prospective doctors to practice under supervision.

Broten also urged additional financial resources in support of "cultural and language education, mentorship and hands on training"; as well as aid to foreign-trained physicians who'd like to pursue another health profession within the Canadian system.

\section{FDA goes global}

$\mathrm{T}$ he US Food and Drug Administration (FDA) is proposing to establish inspection offices in 5 regions of the developing world to enhance its capacity to monitor the safety of drugs, food and medical devices being exported to America.

The expansion of the FDA's reach was proposed June 9, 2008, in a budget amendment seeking an addi- tional US\$275 million increase in the agency's $\$ 2.4$ billion budget for fiscal year 2008/09. The total proposed FDA increase over the previous fiscal year now tops US $\$ 404.7$ million, a $17.8 \%$ budget hike.

Department of Health and Human Services Secretary Mike Leavitt envisioned an FDA presence around the globe, saying the 5 targeted regions are Asia, particularly China and India; Central America; South America; and the Middle East.

The FDA already conducts inspections in Canada. Earlier this year, it told the US Senate Finance Committee that it has conducted 118 inspections of pharmaceutical facilities in Canada since 2002, including 16 in 2007. The FDA and Health Canada have an arrangement under which an auditor from one of the agencies conducts inspections on behalf of both. The FDA is now negotiating a similar arrangement with the European Union. - Wayne Kondro, CMAJ

DOI: $10.1503 / \mathrm{cmaj} .080918$

\section{Secret shame}

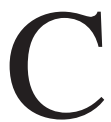

alling artificial food dyes the "secret shame" of the food industry and regulators, the non-profit Centre for Science in the Public Interest has formally petitioned the US Food and Drug Administration to ban Yellow 5, Red 50 and 6 other "certified" artificial food colourings that have been linked to hyperactivity, attention-deficit hyperactivity disorder and other related behavioural problems in children.

"The purpose of these chemicals is often to mask the absence of real food, to increase the appeal of a low-nutrition product to children, or both," stated Centre Executive-Director Michael Jacobson. "Who can tell the parents of kids with behavioural problems that this is truly worth the risk?"

Great Britain's Food Standards Authority has asked food manufacturers to voluntarily switch to safer colourings and is seeking joint European Union action on food dyes because of concerns over
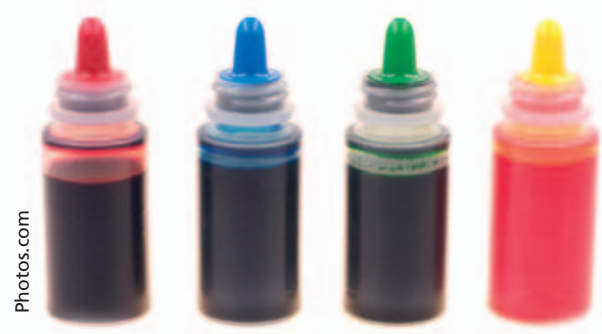
neurotoxic effects.

The Centre for Science in the Public Interest petition also asks for Congressional hearings on artificial food dyes; new warning labels on artificial food dyes (until they're banned); and funding for an Institute of Medicine research project on dyes (www.cspinet.org). 